\title{
İki Farklı Lokasyonda 12 Ayçiçeği (Helianthus annuus L.)Çeşidinin Verim ve Verim Unsurlarının Belirlenmesi
}

\author{
H.Ahmet YILMAZ . Nilgün BAYRAKTAR ${ }^{2}$ \\ Geliş Tarihi : 15.10.1996
}

\begin{abstract}
Özet: Bu çalışma 1993 yılında Şanlıứfa ve Kahramanmaraş ekolojik koşullarında yürütülmüşturr. Çalışmada 12 yeni ayçiçeği çeşitinin verim ve verim unsurları da dikkate alınarak her iki lokasyonda adaptasyonu amaçlanmış ve çalışma "Tesadüf Blokları" deney desenine göre ug tekrarlamalı olarak kuruimuştur. Birinci lokasyonda " Edirne 87", "P-6480" , "Basegene ST 117", "Ekiz II" sirasıyla 2685, 2774,2742,2722,2820 kg/ha yüksek verim sağlarken, ikinci lokasyonda " Edirne 87 " en yüksek verimi (2236 kg/ha) sağlamıștır. Bunúnla birlikte "Dekalb TR 3891 "çeșitinin 1000 tohum ağırliğı ( $85.5 \mathrm{~g}$ ) en yüksek değeri verirken. Kahramanmaraș koşullarında " $V$ 8931" $(71.0 \mathrm{~g})$ en yüksek 1000 tohum ağırliğı değeri göstermiştir. Yağ içeriği bakımından " Dekalb TR 3628. " I. lokalde \% 52.2 oranında en yüksek değeri verirken II. lokalde " Basegene ST 117 " çeşidi \% 51.2 ile en yuksek değerı vermiștir. Bu sonuçlardan; birinci lokalde " Edirne 87", "P-6480" çeşitleri sırasıyla 988 ve $977 \mathrm{~kg} /$ ha en yüksek yağ verimi sağlarken ikinci lokasyonda $788 \mathrm{~kg} / \mathrm{ha}$ lık yağ verimi ile en yüksek değeri " Edirne $87^{\prime \prime}$ çeşidi vermiştir.
\end{abstract}

Anahtar Kelimeler: Ayçiçeği çeşitleri, adaptasyon, lokasyon, verim, verim komponentleri, yağ içeriği

\section{The Study on Yield and Yield Component of 12 Sunflower (Helianthus annuus L.) Cultivars}

Abstract : This research was carried out in two locations, during in 1993. The aim of this study was determined the adaptaion of 12 new sunflower varieties for yield components and yield in two locations, using randomized complied blok design. The over results showed that in the first location the highest yields were obtained with "Edirne 87", "P-6480" "Ekiz I" , Basegene ST 117", "Ekiz II" in the first location were 2685, 2774,2772, $2820 \mathrm{~kg} / \mathrm{ha}$ respectively while in the second location the highest yield obtained with "Edirne 87" $2236 \mathrm{~kg} / \mathrm{ha}$. However 1000 seed weight obtained with "Dekalb TR 3891 ", $85.5 \mathrm{~g}$ Şanliurfa conditions, but in Kahramanmaras conditions the greatest seed weight was " $\mathrm{V} 8931$ " of 71.0 .Wherease the highest oil content was "Dekalb TR 3628 " of $522 \%$ in Şanliurfa, in the second location the highest oil content was $51.2 \%$ "Basegene ST 117 ". From the over result also we found that the highest oil yield "Edirne $87^{\prime \prime}$ and "P-6480" was 988 and $977 \mathrm{~kg} / \mathrm{ha}$ respectively the first location. In the second location the highest oil yield production with "Edirne 87 " of $788 \mathrm{~kg} / \mathrm{ha}$.

Key Words: Sunflower varieties, yield, yield component. oil content, lacations.

\section{Giriş}

Türkiye çok çeşitli yağlı tohumlu bitkilerin yetişmesine elverişli ekolojiiye sahip bir ulkedir. Ancak yağlı tohum ve bitkisel yağ üretimi istenilen düzeyde olmamaktadır. Zorunlu tohumluk ithalatı ve buna bağlı sorunlar üretim ve tüketimi olumsuz etkiliyebilmektedır. Ayçiçeği; yağ bitkisi olarak onemli bir sırada yer alır. Ancak \% 99 yabancı döllendiğinden tohumluk üretımi ve muhafazası zordur (Demir 1990). Yağlı tohumlularda verim artışı ; çeşit, yetiştirilme tekniklen ve sulama ile direkt etkilidir. Son yillarda gerek tüketim ve gerekse hibrit çeşit bakımından Tarım Bakanlığının teşvik ettıği bitkiler içerisinde ayçiçeğine verilen onem giderek artmiş ve yağı : sağlıklı yağ olarak da ülkemizde geniş bir kullanım alıșkanlığı doğurmuştur

Ayçiçeği ve alternatif yağlı tohumlular için "GAP" bölgesi ve "Doğu Akdeniz" Bölgesi onemli bir şanstır. Buralarda hibrit tohumluktan beklenen verim artışının yüksek olması: çeşitlerin ekolojik koşullara uygunluk göstermesine, yetiştirilme tekniklerınin yöre ureticilerı tarafindan iyi bilinmesine, pazar ve sanayilerinin oluşturulmasına bağlıdır (Kolsarıcı ve Ark 1990). Bu ikı ilde yapılan denemelerle ayçiçeğinin yetiştirilme olanakları araştırılmıs ve gelecekte bu bölgelere verimli yenı çeşitlerin onerilmesinnin mümkün olup olmayacağı. kaynak oluşturulmaşı açısından amaçlanmıştır.

llisulu ve ark (1982), 14 Ayçıçeği çeşidi ile Ankara ve Van ekolojik koșullarinda suluda yapmış oldukları denemelerde dekara tohum veriminin $198-290 \mathrm{~kg}$, bitki boyunun $110-160 \mathrm{~cm}$, tabla çapının $22-25 \mathrm{~cm}$, yağ oranının \% 31-44, kabuk oranini \% 26-39, 1000 tane ağırliğına $65-92 \mathrm{~g}$, sap verimini ise dekara $401-630 \mathrm{~kg}$ arasında kaydettiklerini ifade etmişlerdir.

Gumenynk ve Sytrik (1976). "Yüksek verim ve yağ ıçeriği için "Ayçıçeğı ıslahı" konulu çalışmalarında "Kharkousky 1000 " isimli varyeteyi denemeye almış ve dekara $275-288 \mathrm{~kg}$ tohum ve \% 56-58 arasında yağ oranı saptatıklarıni ifade etmişlerdir

Ekiz (1980 a) Ankara koşuillarinda denemeye aldiğı "V. $1646^{\prime}$ ve "V.6540" çeşitlerinde dekara tohum verimini sirasiyla $212.3 .219 .5 \mathrm{~kg}$; sap verimini 374.1 ve $421.6 \mathrm{~kg}$ 
tabla çapını $18.9,18.4 \mathrm{~cm}$; bitki boyu 171.8-185.9; 1000 tohum ağırlığını 76.3-81,2 g; kabuk oranını \% 25.66 . 25.83 ;yağ oranını ise $\% 43.48$ ve $\% 43.46$ olarak kaydettiğini belirtmiştir.

Ekiz ( 1980 b) Ankara ve Lüleburgaz koşuliarında yürütülen denemelerde "V.8931" ve "Peredovik" çeşitlerini dekara tohum verimini sırasıyla $187,172 \mathrm{~kg}$; tabla çapini $17.4,17.0 \mathrm{~cm}$; bitki boyunu $144,142 \mathrm{~cm} ; 1000$ tohum ağırlığını $58.9,61,6 \mathrm{~g}$; kabuk oranını \% 24,31, \% 24,50 ve yağ oranını $\% 44.18, \% 43.35$ olarak elde etmiștir.

Potler ve Mcloud (1985), Avustralya'da denemeye aldıkları ayçiçeği çeşitlerinde tohum veriminin 155-222 $\mathrm{kg} /$ da : yağ oranının \% $43-48$, arasında değiştiğini standart "Vniimk 8931" çeşidinde ise sırasıyla $178 \mathrm{~kg} / \mathrm{da}$ $178 \mathrm{~kg} / \mathrm{da}$ ve \% 46 olarak kaydedildiğlini ayrica dekara yağ veriminin de $75-110 \mathrm{~kg}$ hibritlerde $130 \mathrm{~kg}$ 'a kadar değişebildeğini bildirmişlerdir.

Majid ve Schneifer (1987), Kuzey Dakota eyaletinde denemeye alınan "Sigco-SD" " "Cargil-SD" "894-SH" ve "Cargil-SH" çeşitlerinde sırasıyla tohum verimi $178,207,183$ ve $201 \mathrm{~kg} / \mathrm{da}$, yağ oranları $\% 45,44,45$ ve $47 ; 1000$ tohum ağırlığı ise $37,47,37$ ve $41 \mathrm{~g}$ olarak elde etmişlerdir

Er ve Işık (1988) OrtaAnadolu koşullarında "V.6540" çeşidini farklı ekim zamanlarında dekara tohum verimini 203-320 kg; sap verimini $507-621 \mathrm{~kg}$; bitki boyunu 181 $216 \mathrm{~cm} ; 1000$ tohum ağırlığını ise $63-72 \mathrm{~g}$ arasında kaydetmişlerdir.

Oral ve Kara (1989), Doğu Anadolu bölgesi koşullarında denemeye alınan "V.6540" , "Armavirsk", " GK-70" ve "V 8931" çeşitlerinde bitki boyunu 114-163 $\mathrm{cm}$, tabla çapını $21-23 \mathrm{~cm}, 1000$ tohum ağırlığını $52-76$ g, yağ oranını $\% 43-48$, kabuk oranını $\% 29-31$, tohum verimi ise dekara $267-340 \mathrm{~kg}$ arasında elde ettiklerini belirtmişlerdir.

Sezer (1991), Tekirdağ ekolojik şartlarında değișik ayçiçeği melezlerinin denendiği araştırmada i dekara tohum veriminin $197-295 \mathrm{~kg}$ ve sap veriminin $358-430$ $\mathrm{kg}$, bitki boyunun $120-148 \mathrm{~cm}$ tabla çapının $17.8-21.0$ $\mathrm{cm}, 1000$ tohum ağırlığının $69.22-72.0 \mathrm{~g}$; kabuk oranının \% 26.01- 29.34 yağ oranının ise \% 39.2 .0 arasında değiştiğini ifade etmiştir.

Camcı (1992), Ankara ve Afyon koşullarında denemeye alınan ayçiçeği çeşitlerinde deneme sonuçlarına göre tohum verimi $192-312 \mathrm{~kg}$; dekara yağ verimi $73-124 \mathrm{~kg}$; sap verimini $720-430 \mathrm{~kg}$; bitki boyu $173-91$ $\mathrm{cm}$; tabla çapı $19-14 \mathrm{~cm} ; 1000$ tohum ağırlığını $61-76 \mathrm{~g}$ ; kabuk oranı ise $\% 26-33,28-31$ arasında saptandığını rapor etmiştir

Yılmaz ve Emiroğlu (1995), Tokat ekolojik koşullarında12 $F_{1}$ ve 2 kontrol çeşit olmak üzere, toplam 22 çeşitle yapmış oldukları çalışmada, bitki boyunu 114 $167 \mathrm{~cm}$; tabla çapını $16,6-22.7 \mathrm{~cm} 1000$ tohum ağırığını $51.3-77,7 \mathrm{~g}$; kabuk oraninı $\% 32.6-22.8$, yağ oranını $\% 37.1-46.0$; sap verimini $233-549 \mathrm{~kg} / \mathrm{da}$; dane verimini $107-289 \mathrm{~kg} / \mathrm{da}$; yağ verimini $41-127 \mathrm{~kg} / \mathrm{da}$ arasında tespit ettiklerini bildirmişlerdir.

\section{Materyal ve Yöntem}

Her iki lokasyonda ; farklı kuruluşların tavsiye edilen çeșitleri denemeye alınmıştır. "Ekiz -1" "Ekiz-2 (Üretim izninde)" Ankara Universitesi Ziraat Fakültesi Tarla bitkileri bölümü tarafından geliştirilmiş Orobaş'a (Orobanche cumana Wallrr L.) dayanikiı ince kabuklu, yağlık sentetik çeşitlerdir. "Edirne 87 " Trakya Tarımsal Araştırma Enstitüsü tarafından geliştirilmiş yerli hibrit çeşit."Vniimk 8931" Ülkemizde sıkça denenen ancak orobanşa dayanıksız, verimli ayçiçeği denemelerinde standart olarak alınan bir çeşit. "Dekalb TR 3891", "Dekalb TR 3628" Dekalb tohumculuk șirketinden " $P$. 6480", "P-6431", "P-3628" Pioneer Tohumculuk şirketinden " Basegene ST 115", "Basegene ST 117" Basegene tohumculuk şirketinden ve "IS-3330" Güneş tohumculuk şirketinden elde edilen $A B D$ ve Fransa orjinli hibrit çeşitlerdir. Denernede"Ekiz -1", "Edirne 87" ve "P. $6480^{n}$ çeşitleri standart olarak alınmıştır. Bu çeşitler kuruluşları tarafından iyi vasıflı olarak tavsiye edilmişlerdir. "V.8931" çeşidi ülkemizdeki tüm ayçiçeği denemelerinde kontrol olarak alınan bir çeşit olmakta birlíkte Trakya ve diḡer ayçiçeği ekili bölgelerde orobanşa dayanıksız olduğundan önemli verim azalışları görülmektedir

Denemeler Şanlıurfa (Koruklu Deneme istasyonunda) ve Kahramanmaraş ( Tarla Bitkileri Üretme istasyonunda ) kurulmuş olup Her Íki lokasyona ait iklim ve toprak verileri Çizelge 1 ve Çizelge 2 de verilmiştir.

\section{Yöntem}

Denemeler her iki lokasyonda da Tesaduf blokları deneme deseninde dört tekerrürlü olarak kurulmuştur. Ekim sıklığı $60 \mathrm{~cm}$ (sıra arası) $\times 50 \mathrm{~cm}$ (sıra uzeri) olarak $5 \mathrm{~m} \times 6 \mathrm{~m} 30 \mathrm{~m}^{2}$ parsel alanı içerisinde 10 sirali ekim yapılmıştır (kenar tesiri hariç 100 adet bitki yetiştirildi). Şanlıurfa'da ekim 27.4.1993, Kahramanmaraş'da ise 28,4.1993 tarihinde ekim yapılmıştır, I.Bölgede iki kez çapa 7 kez sulama yapılmış II. Bölgede ise 2 kez sulama 5 kez sulama yapılmıștır. Her iki bölgede bogaz doldurma işlemi yapılmış gübreleme ise yapilmamiştır. Illk tabla oluşumu

I. bölgede 15.6.1993 ikinci bölgede ise 7.7.1993 tarihinde olmuştur Her iki bölgedeki denemelerde orobanş türlerine rastlanılmamıştır. I. lokasyonda ilk hasat tarihi 7.9.1993, Il.lokasyonda ise 20.9.1993 olarak kaydedilmiştir.

\section{Verilerin Elde Edilmesi ve Değerlendirme Metodları}

Verilerin elde edilmesinde Kara (1984) ve Sezer (1987) 'in kullandığı yöntemler esas alınarak; her parselde kenar sıra dışındaki tüm bitkiler hasat edilmiş , tesadüf olarak seçilen 30 bitkide tabla çapı ve bitki boyu ölçülmüş, parsele tohum verimi ve tohumsuz tabla ve sap ağırlığı kaydedilmiştir. Her parsele ait tohumluktan $4 \times 100$ 
Çizelge 1. Sanlıurfa ve Kahramanmaraş illerinin 1993 yilına aìt iklim verileri

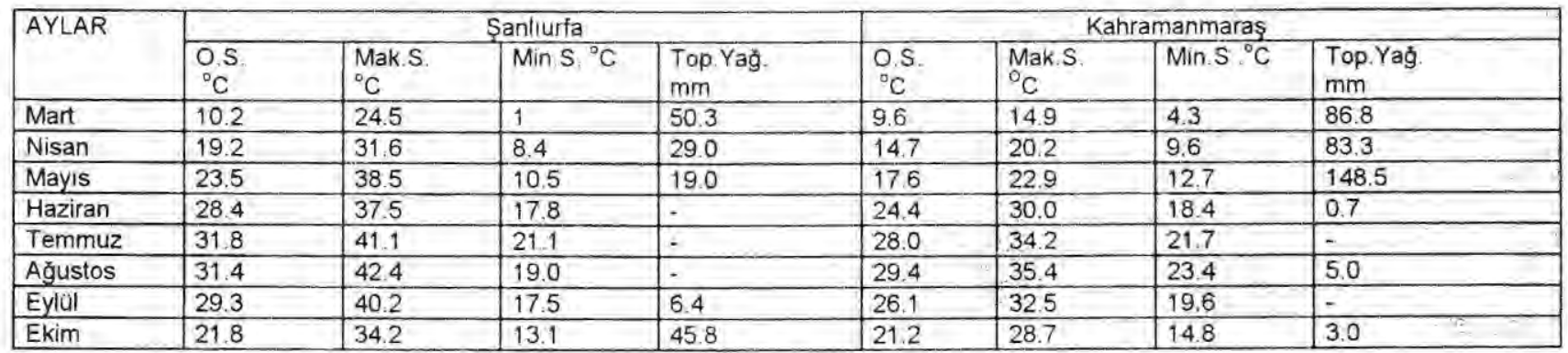

Çizelge 2. Deneme y

erlerine ait toprak analiz

\begin{tabular}{|l|l|l|l|l|l|l|l|}
\hline & Derinlik(cm) & $\begin{array}{l}\text { Su ile Doyma } \\
(\mathrm{CL})\end{array}$ & $\mathrm{pH}$ & $\begin{array}{l}\text { Kireç } \\
(\%)\end{array}$ & $\begin{array}{l}\text { Toplam Tuz } \\
(\%)\end{array}$ & $\begin{array}{l}\text { Organik M } \\
(\%)\end{array}$ & $\begin{array}{l}\text { Y.Fosfor (kg/da) } \\
\text { Şanliurfa }\end{array}$ \\
\cline { 2 - 7 } & $0-20$ & 57 & 7.55 & 20.2 & 0.060 & 1.1 \\
\cline { 2 - 7 } & $20-40$ & 56 & 7.54 & 22.2 & 0.065 & 1.0 \\
\hline \multirow{2}{*}{ Kahramanmaras } & $0-20$ & 54 & 7.50 & 9.8 & 0.080 & 1.4 \\
\cline { 2 - 7 } & $20-40$ & 54 & 7.58 & 11.4 & 0.070 & 1.2 \\
\hline
\end{tabular}

adet tohum örneği alınmış ve 1000 tohum ağırlığı, kabuk ve iç oranı ile birlikte yağ oranı analizi NMR yontemine göre Konstantinous ve ark (1973) ve Marquard (1980)'ne göre Ege Úniversitesi Ziraat fakultesi Merkez Labaratuarında saptanmıştır Yağ oranları ayrıca tohum verimleri esası uzerinden yağ verimleri de bulunmuștur. Elde edilen veriler MSTATC paket proğramina gore değerlendirilmiştir

\section{Bulgular ve Tartışma}

Tohum Verimi: Her iki lokasyona ait tohum verimı Çizelge 3 ve Çizelge 4' de sunulmuştur. Incelendiğinde Çeşitler arası ve Çeșit $\times$ Yer interaksiyonu \% 1 düzeyinde önemli bulunmuştur. I lokasyonda "Ekiz II", " "P-6480" "Ekiz I", "Edirne 87" en yüksek verimleri vermişlerdir $(268.5-282.0 \mathrm{~kg})$ "Dekalb TR 3628 " çeşidinden ise en dusşü $(183.3 \mathrm{~kg})$ verim alınmıştır. II lokasyonda "Edırne 87" "P-3628" ve "Dekalb TR 3628" çeşitlerinin verim ortalamaları yüksek $(203.2-223.6 \mathrm{~kg})$ olmuş, diğer çeşitler ve ozellikle "Basegene- ST117" (117.3 kg) ise dusşuk verim vermişlerdir. Çeşitlerin I. lokasyonda daha fazla verimli iken 11. lokasyonda standartı geçen ( $P$ 3628 ,Dekalb TR 3628 ve 3891) çeşitler oldug̃u gözlenmiştir. Çeşitlerin farklı lokasyonlarda farklı verim sonuçları verdiği fakat "Edirne -87" ve "P 6480" çeşitlerinin her iki lokasyonda da verimli olduğu gözlenmiştir. I. lokasyonda (Şanlıurfa), "Ekiz -2" çeşidi "Ekiz 1" "e göre daha yüksek verim vermiş ve daha iyi uygunluk sag̃lamıştır. Bu sonuçla "Edirne- 87 " ve "P-6480" çeșitlerinin daha geniş bolgelere adapte olabileceği , diğer çeşitlerin ise ancak belirli ekolojilerde verimli olabilecekleri söylenebilir. (Şekil 1) Çeşit farklılığın aynı lokasyonlarda veya farklı lokasyonlarda ozellikle tohum verimi üzerine çok etkili olabildiği ve ekolojik uygunluğun ise önemli bir faktör olduğu kabul edilmektedir. (ilisulu ve Arslan 1975, Ekiz 1980 b. Oral ve Kara 1989, Camcı 1992, Yilmaz ve Emiroğlu 1995).
Sap verimi: Çeşitlerin sap verimleri ile ilgili test so-

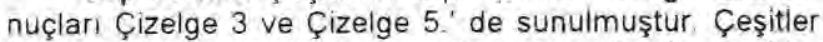
iki lokasyonda da farklı sonuçları vermişlerdir. Çeşitier arası ve çeşit $x$ yer interaksiyonu bakımından sap veriminde istatistiksel olarak \% 1 düzeyinde önemlilik kaydedilmiştir. Sap verimi I. lokalde (Şanlıurfa) dekara ssgf ejktojerfdf fkjh fsjhwerj $\times 248.3-343.8 \mathrm{~kg}$, II lokalde (K aras $278,8-509,5 \mathrm{~kg}$ arasında değişmiştir. Tüm çeşitlerin I. lokaldeki sap verimleri II lokale göre düşük olmuş-tur.

Gerçi her iki lokalde bitki boyu ve tabla çapı bakımından incelendiğinde 11 . lokalde bitkilerin biraz daha boylu oldukları, ancak ikinci lokalde tabla çapının daha geniş olduğu görülmekle birlikte yapilan gözlemlerde I. lokalde sap çapının daha ince, II. lokalde çapin daha kalınlaştığı bitki sapının daha ağır olduğu, l.lokalde òzellikle kuşlar tarafından tabla yeniğinin çok oldữgu sadece salt bitki uzunluğunun alındığı, II lokalde yenik tabla az olduğundan sap ağırlığının tohumsuz tabla + bitki boyu uzerinden alındığı bununda sap verimini yükselttiği soylenebilir. Çünkü sap veriminin düşük veya yüksek olması : parseldeki tûm bitkilerin ağırlığına bağlı bir ölçümdür. Materyaller orta - uzun özellikte olup diğer araştırıcılara göre sap verimi daha düşük veya yakın olmuştur ( Ilisulu ve Arslan 1975, Er ve Işık 1988, Camc। 1992 , Yilmaz ve Emiroğlu 1995).

1000 tohum ağırlığı : Çizelge 3 ve Çizelge 6 'de çeşitlerin tohum ağırlığına ilişkin analiz ve test sonuçlan verilmiştir. Tohum ağırlığı bakımından Çeşit $x$ Yer interaksiyonu istatistiksel olarak \% 1 düzeyinde önemli bulunmuştur I. lokalde 1000 tohum ağırlığı 60.6- 85.5 g. II. lokalde $54.01-71.0 \mathrm{~g}$ arasında değişmiştir. I. lokalde "Dekalb TR 3891 " (85.5 g), II lokalde ise "V8931 " çeşidi dolgun tane oluşturmuş, iki yer ortalamasına göre "Dekalb Tr 3891 "ve Basegene ST 117" çeşitleri en. yüksek değerleri oluşturmuştur. Iklim ve toprak yapısına bağlt olarak değişen döllenme süresi ve çeşit özelliğinin tohum iriliği üzerine önemli etkisi olduğu söylenebilir 
Çizelge 3. Incelenen özelliklere ait varyans analiz sonuçları ve varyasyon kaynakları.

\begin{tabular}{|c|c|c|c|c|c|c|}
\hline $\begin{array}{r}\text { Varyasyon Kaynakları } \Rightarrow \\
\text { U Ozellikler }\end{array}$ & Yer & Tekerrär & Çeşit & Çeşit*'Yer & Hata & C.V $(\%)$ \\
\hline Tohum verimi & $153784.0^{*}$ & 1049.4 & $3495.5^{* *}$ & $4841.9^{* \star}$ & 349.2 & 8.87 \\
\hline Sap verimi & $500837.0^{* *}$ & 5178.0 & $9226.4^{* \star}$ & $12678.8^{* *}$ & 1511 & 10.55 \\
\hline Yağ verimi & $19.3^{*}$ & 95.4 & 403.2 & 465.1 & 69.3 & 10.9 \\
\hline Kabuk oranı & $2.2^{*}$ & 8.7 & $20.3^{* *}$ & $9.3^{* *}$ & 1.945 & 5.24 \\
\hline Bitki boyu & 5.636 & 299.5 & $244.1^{*}$ & $710.6^{\star \star \star}$ & 138.3 & 7.54 \\
\hline Tabla çapı & $139.3^{\star \star}$ & 10.0 & $33.5^{* *}$ & 2.1 & 1.4 & 5.62 \\
\hline Yağ orani & 0.02 & 4.5 & $14.6^{* *}$ & $6,1^{* *}$ & 0.0 & 2.02 \\
\hline
\end{tabular}

*) $\% 5$ düeyinde

**) \%1 duzeyinde

Çizelge 4. Denemeye alınan ayçiçeği çeşitlerine ait tohum verimi değerleri ve oluşturduğu Duncan grupları

\begin{tabular}{|c|c|c|c|}
\hline \multirow[t]{2}{*}{ Çeşitler } & \multicolumn{3}{|c|}{ TOHUM VERIMI } \\
\hline & S..Urfa & K.Maraş & Ortalama \\
\hline EDIRNE 87 & $268.5 a$ & 223.6 be & $246.1 \mathrm{a}$ \\
\hline $\begin{array}{l}\text { DEKALB TR } 3891 \\
\text { DK }\end{array}$ & 254.6 ac & $190.3 \mathrm{eh}$ & $222.4 a b c d$ \\
\hline PIONEER 6480 & $277.4 \mathrm{a}$ & $197.0 \mathrm{eh}$ & $237.3 \mathrm{ab}$ \\
\hline BASEGENE ST 115 & $259.1 \mathrm{ab}$ & $166.7 \mathrm{gj}$ & $\begin{array}{l}212.8 \\
\text { bcde }\end{array}$ \\
\hline EKIZ1 & $274.2 \mathrm{a}$ & $149.0 \mathrm{ik}$ & \begin{tabular}{|l|}
211.6 \\
bcde
\end{tabular} \\
\hline BASEGENE ST 117 & $272.2 a$ & $117.3 \mathrm{k}$ & 194.7 ef \\
\hline PIONEER 6431 & $254.8 \mathrm{ac}$ & $151.2 \mathrm{Ik}$ & $203.0 \mathrm{de}$ \\
\hline VNIIMK & $218.8 \mathrm{cf}$ & $161,6 \mathrm{hj}$ & 190.2 ef \\
\hline PIONEER 3628 & $250.8 \mathrm{ad}$ & $213.6 \mathrm{df}$ & $232.2 \mathrm{abc}$ \\
\hline EKIZ II & $282.0 \mathrm{a}$ & $135.7 \mathrm{jk}$ & $208.9 \mathrm{cde}$ \\
\hline $\begin{array}{l}\text { GUNES TOH. IS } \\
3330\end{array}$ & $213.2 \mathrm{df}$ & $138.7 \mathrm{jk}$ & $175.9 \mathrm{f}$ \\
\hline DEKALB TR 3628 & $183.3 \mathrm{fl}$ & $203.2 \mathrm{eg}$ & $193.3 \mathrm{ef}$ \\
\hline Ortalama & 250.7 & 170.7 & 210.7 \\
\hline O.D. & 0.01 & 0.01 & 0.01 \\
\hline
\end{tabular}

Çizelge 5. Denemeye alınan ayçiçeği çeşitlerine ait sap verimi değerleri ve oluşan Duncan grupları.

\begin{tabular}{|c|c|c|c|}
\hline \multirow[t]{2}{*}{ Çeşitier } & \multicolumn{3}{|c|}{ Sap Verimi (kg/da) } \\
\hline & S.Urfa & K.Maras & Ottalama \\
\hline EDIRNE 87 & 295.0 ijk & 480.5 abcd & $387.8 \mathrm{a}$ \\
\hline DEKALB TR 3891 DK & 325.8 hijk & 458.0 abcde & $391.9 \mathrm{a}$ \\
\hline PIONEER 6480 & $295.0 \mathrm{ijk}$ & 491.3 abc & $393.1 \mathrm{a}$ \\
\hline BASEGENE ST 115 & $248.3 \mathrm{jk}$ & 477.3 abcd & $362.8 \mathrm{ab}$ \\
\hline EKIZ1 & $270.0 \mathrm{ijk}$ & $509.5 a$ & $389.8 \mathrm{a}$ \\
\hline BASEGENE ST 117 & 263.8 ijk & $495.8 \mathrm{ab}$ & $379.8 \mathrm{a}$ \\
\hline PIONEER 6431 & 330.0 glinj & 416.0 bedef & $373.0 \mathrm{a}$ \\
\hline VNIIMK & $243.8 \mathrm{k}$ & $379.5 \mathrm{efgh}$ & $311.6 \mathrm{bc}$ \\
\hline PIONEER 3628 & $343.8 \mathrm{fghi}$ & 412.8 cdef & $378.3 \mathrm{a}$ \\
\hline EKIZ II & 315.0 hijk & 483.8 abcd & $399.4 a$ \\
\hline GLNES TOH. IS 3330 & 300.3 hijk & 278.8 ijk & $289.5 \mathrm{c}$ \\
\hline DEKALB TR 3628 & $325.3 \mathrm{hijk}$ & $406.3 \mathrm{defg}$ & $365.8 \mathrm{a}$ \\
\hline Ortalama & 296.3 & 440.7 & 368.5 \\
\hline Ö.D. & 0.01 & 0.01 & 0.01 \\
\hline
\end{tabular}

Çizelge 6. Denemeye alınan ayçiçeği çeşitlerine ait 1000 tohum ağırlığı ve Duncan grupları

\begin{tabular}{|l|l|l|l|}
\hline \multirow{2}{*}{ Çeşitler } & \multicolumn{3}{|c|}{1000 tohum ağırlı̆̆ı (g) } \\
\cline { 2 - 4 } & S.U.fa & K.Maras & Ortalama \\
\hline EDIRNE 87 & $69.1 \mathrm{cg}$ & $61.5 \mathrm{el}$ & $65.3 \mathrm{ad}$ \\
\hline DEKALB TR 3891 DK & $85.5 \mathrm{a}$ & $58.9 \mathrm{gl}$ & $72.2 \mathrm{a}$ \\
\hline PIONEER 6480 & $68.9 \mathrm{cg}$ & $54.0 \mathrm{l}$ & $61.4 \mathrm{~cd}$ \\
\hline BASEGENE ST 115 & $60.6 \mathrm{el}$ & $66.0 \mathrm{dh}$ & $63.2 \mathrm{bd}$ \\
\hline EKIZ1 & $79.8 \mathrm{ac}$ & $58.9 \mathrm{gl}$ & $69.4 \mathrm{ab}$ \\
\hline BASEGENE ST 117 & $79.4 \mathrm{ac}$ & $65.4 \mathrm{dh}$ & $72.4 \mathrm{a}$ \\
\hline PIONEER 6431 & $81.4 \mathrm{ab}$ & $56.4 \mathrm{hl}$ & $68.9 \mathrm{ac}$ \\
\hline VNIIMK 8931 & $67.4 \mathrm{dh}$ & $71.0 \mathrm{bf}$ & $69.2 \mathrm{ab}$ \\
\hline PIONEER 3628 & $73.4 \mathrm{bd}$ & $60.6 \mathrm{fl}$ & $67.0 \mathrm{ad}$ \\
\hline EKIZ II & $71.8 \mathrm{be}$ & $58.6 \mathrm{gl}$ & $65.2 \mathrm{ad}$ \\
\hline GUNES TOH. IS 3330 & $71.1 \mathrm{bf}$ & $67.1 \mathrm{dh}$ & $69.1 \mathrm{ab}$ \\
\hline DEKALB TR 3628 & $65.7 \mathrm{dh}$ & $58.8 \mathrm{l}$ & $59.7 \mathrm{~d}$ \\
\hline Ortalamalar & 72.8 & 61.0 & 66.9 \\
\hline O.D. & 0.01 & 0.01 & 0.01 \\
\hline
\end{tabular}

Illisulu ve Arslan (1975), değişik çeşitlerin denendiği farklı lokasyonlarda 1000 tohum ağırlığını 65-92 g; Ekiz (1980 a), 76.3-81.2 g, Ekiz (1989 b) 58.9-61.6 g, Er ve Işık (1988) 63-72 g, Sezer (1991) 69.2-72.0 g, Camcı (1992) $63.76 \mathrm{~g}$, Yilmaz ve Emiroğlu (1995) ise 51.3$77.7 \mathrm{~g}$ olarak kaydederken bu araştırmada elde edilen verilerin lokasyon ve çeşit farklılıklarına rağmen uygunluk gösterdikleri görülmektedir. Özellikle I, lokalde tohum dolgunluğu daha yüksek bulunmuştur.

Içte yağ oranı: Çizelge 3 ve Çizelge $7^{\prime}$ de içte yağ oranına ait değerler sunulmuştur. Çeşitler arası ve Çeşit $x$ Yer interaksiyonu \% 1 düzeyinde önemlilik göstermiştir. | lokalde yağ oranı $\% 46.8$ - 52.2, II. lokalde $\% 49.3-51.2$ arasında değişmiștir. "Dekalb TR 3628 " ( \% 52.2) , "V$8931 "$ ( 51.6) ve "Basegene ST 117" (51.2) çeşitleri diğerlerine göre daha yüksek değerler vermişlerdir. Içte yağ oranı; ayçiçeği yetiştirme ve ıslahında önemli verim ögelerinden biri olup birim alanda yağ verimine etkilidir. Ülkemizde değişik çeşitlerde farklı lokasyonda araştırmalar yapmış olan araştırıcılar içte yağ oranını \% 39.2-48.0 arasında elde etmişlerdir. Bu araştırmada yağ oranı ortalaması \% 47.0-51.1 arasında değişmiştir. Farklı koşullara ve çeşitleree rağmen içte yağ oranı yüksek olmuştur. Çeşitler yağlık olarak tavsiye edilebilmektedir (özellikle " Dekalb TR 3628 ", "Edirne 87", "P-6480 ve 6431", "IS 3330 "). 
Çizelge 7. Denemeye alinan ayçiçeği çeşitlerıne ait ıçte yag̉ oranları ve Duncan grupları

\begin{tabular}{|l|l|l|l|}
\hline \multirow{2}{*}{ Çeşitler } & \multicolumn{2}{|c|}{ lçle yağ oranı (\%) } \\
\cline { 2 - 4 } & Sanliurfa & Kahramanmaras & Ortalama \\
\hline EDIRNE 87 & $51.0 \mathrm{ac}$ & $50.3 \mathrm{a}$ & $50.6 \mathrm{ab}$ \\
\hline DEKALB TR 3891 DK & $50.9 \mathrm{ac}$ & $493 \mathrm{ae}$ & $50.1 \mathrm{ab}$ \\
\hline PIONEER 6480 & $49.2 \mathrm{ae}$ & $50.3 \mathrm{ad}$ & $49.8 \mathrm{ab}$ \\
\hline BASEGENE ST 115 & $48.7 \mathrm{be}$ & $49.9 \mathrm{ae}$ & $49.3 \mathrm{ac}$ \\
\hline EKIZ1 & $47.2 \mathrm{de}$ & $46.8 \mathrm{e}$ & $47.0 \mathrm{~d}$ \\
\hline BASEGENE ST 117 & $46.8 \mathrm{de}$ & $51.2 \mathrm{ab}$ & $491 \mathrm{bc}$ \\
\hline PIONEER 6431 & $49.9 \mathrm{ae}$ & $51.0 \mathrm{ac}$ & $50.4 \mathrm{ab}$ \\
\hline VNIIMK 8931 & $51.6 \mathrm{ab}$ & $49.3 \mathrm{ae}$ & $50.4 \mathrm{ab}$ \\
\hline PIONEER 3628 & $50.3 \mathrm{ad}$ & $49.6 \mathrm{ae}$ & $50.0 \mathrm{ab}$ \\
\hline EKIZ II & $47.7 \mathrm{ce}$ & $47.2 \mathrm{de}$ & $47.4 \mathrm{~cd}$ \\
\hline GUNES TOH.IS 3330 & $51.2 \mathrm{ab}$ & $51.0 \mathrm{ac}$ & $51.1 \mathrm{ab}$ \\
\hline DEKALB TR 3628 & $52.2 \mathrm{a}$ & $50.7 \mathrm{ac}$ & $51.4 \mathrm{a}$ \\
\hline Ortalamalar & 49.7 & 49.7 & 49.7 \\
\hline O.D & 0.01 & 0.01 & 0.01 \\
\hline
\end{tabular}

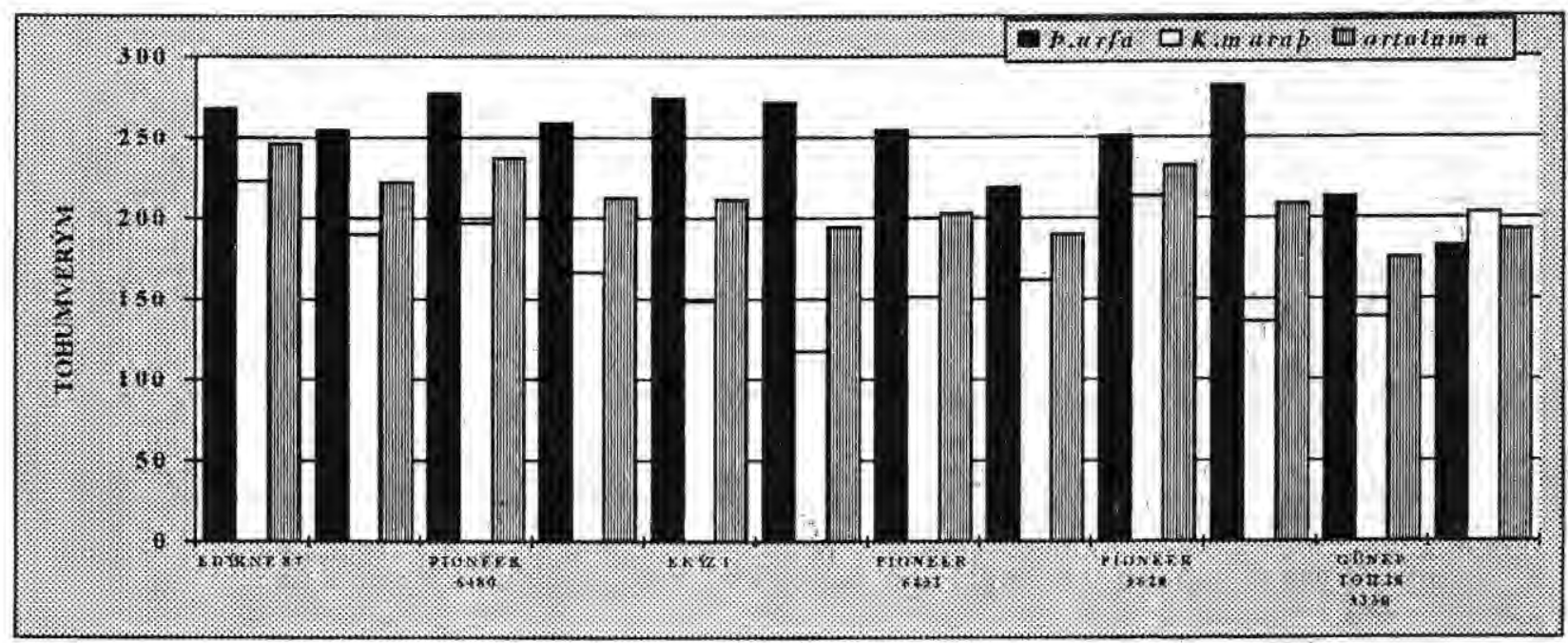

Şekil 1. Farklı lokasyonlardaki tohum verimi ve ortalama değerleri.

Yağ verimi: Çizelge 3 ve Çizelge 8 'da yağ verımine ait analiz ve test sonuçları verilmiştir. 1. lokalde dekara yag̃ verimi $70.5-98.8 \mathrm{~kg}$. II. lokalde ise $44.4-78.8 \mathrm{~kg}$ arasında değişmiştir. I lokalde "Edirne 87", "P-6480" "P6431", "Ekiz-I"; II. lokalde ise "Edirne 87", "P-3628", "Dekalb TR 3628" oldukça iyi sonuçlar vermişlerdir. Ayçiçeğinde birim alandan yüksek yağ verimı amaçlanmaktadır. Yağ verimi; tohum verimi, tohum iç oranı ve yağ oranı ile di rekt etkili olan, artan veya azalan bir ógedir. I. lokalde dekara yağ verimi ortalama $90.6 \mathrm{~kg}$ iken II. lokalde $62.2 \mathrm{~kg}$ olmuştur Ayn çeşitlerın kullanılmasına rağmen yer faktörünün tohum verımı uzerine çok etkili olduğu görülmektedir. Potler ve Mclound (1985) dekara yağ verimi $75-110 \mathrm{~kg}$, hibritlerde ise 130 kg'a kadar değişebileceğini, Camcı (1992) ise Ankara veAfyon koşullarında farklı ayçiçeği çeşitlerinın dekara yağ verimini 73 - $124 \mathrm{~kg}$, Yılmaz ve Emiroğlu (1995) ise 41-177 kg/da kadar değişebileceğini belirtmişlerdir. Farklı ekolojik çevre özellikle yağış durumu yağ verimini etkiler Ancak I. lokasyon verileri bu araştırıcilara uygunluk gösterirken, II lokasyon deg̃erleri daha düşuk olmuştur Keza yağ verimı bakımından çeşitler arasında farklı verim performansıda kaydedilmiştir. Bazı çeşitler lokasyona uygunluk gösterirken bazılarında verim dusşuklügua oldukça açık gorülmüştür. Örneğin "P-serisi" verimli olmuş. "Basegene "serisi, "Ekiz-1 ve Ekiz-2" verim oldukça farklı durum göstermiştir (Çizelge 6).

Kabuk Oranı : Çizelge 3 ve Çizelge 9 incelendiğinde kabuk oranına ait değerler ve testler görülmektedir. Kabuk oranında, Çeşitler , Çeşit $\times$ Yer interaksiyonu bakımından ıstatistiki olarak \% 1 dúzeyinde önemli fark kaydedilmiştir. I lokalde kabuk oranı \% 23.6-31.4, II lokalde \% 22.7-29,9 açısında deg̉işmiştir. "Edirne 87". "P-6480" ve "P-3628" çeşitlerinin dişindakilerde ince kabukluluk özelliği gorülmektedir. Kabuk oranı genetik yapıya bağlı oimakla birlikte Çevre $x$ Genotip interaksiyonunun ortaya koyduğu bir ozelliktir. Çeşitlerin hepsi ayrı bir genotipik yapıya sahip olduklarından, her birinın ayrı sonuç oluşturması gayet doğaldır. Ekiz (1980 a) farklı çeşitleri kullandığı denemelerde kabuk oranını \% 28-66, Oral ve Kara (1989) \% 29.0-31.0, Sezer (1991) \% $26.01-2934$, Camcl (1992) \% 28.26-33, Yilmaz ve Emiroğlu (1995), \% 32.6-22.8 arasinda kaydettiklerini ifade etmiş olup bu denemede elde edilen veriler uygunluk góstermiş ayrica hibrit çeşitler olmalarına 
rağmen kabuklu çeşit özelliğini muhafazası etmişler ( $V$ 8931 ve Ekiz -1)

Bitki boyu : Çizelge 3 ve Çizelge $10^{\prime}$ da bitki boyuna ait varyans analizi ve Duncan kontrolu sunulmştur. I. lokalde bitki boyu ortalaması $136.3-174.6 \mathrm{~cm}$, II lokalde ise 143.9-183.3 cm arasında değişmiştir. "P-6431", "V8931", "Dekalb TR 3628 " çeşitleri her iki lokasyonda oldukça farklı boy ortalamaları sunmuş iken "Ekiz -1", Ekiz-2" ve "Edirne 87" çeşitleri ise daha satabil bir durum göstermişlerdir. Yağlık çeşitlerde özellikle bitkilerde aşırı boya kaçma istenmez. Mekanizasyon ve olumsuz iklim koşulları nedeniyle uzun boylulukta verim kayıpları olabilmektedir. Çeşitler arasında bitki boyunda istatistiki olarak \% 5 önemlilik bulunurken Çeşit $\times$ Yer interaksiyonu bakımından \% 1 düzeyinde önemlilik kaydedilmiştir. Çeşitlerin boyları normal veya normal uzun sınırlar içerisinde kalırken, yetiştiricilikte devrilme gibi bir problemle karşılaşılmamıştır. Farklı çeşit ve ekolojilerde Ilisulu ve Arslan (1975) bitki boyu ortalamasını 110-160 cm, Ekiz (1980 b) 142-144 cm, Er ve Işık (1988) 181-216 Oral ve Kara (1989) $114-163 \mathrm{~cm}$ Camcl (1992) 103-173 $\mathrm{cm}$, Sezer (1991) 120-148 cm , Yılmáz ve Emiroğlu (1995) ise $114-167 \mathrm{~cm}$ arấsında elde ettiklerini ifade etmişlerdir. Bu denemede çeşitlerin hem genetik farklılığı hemde çevre şartlarından kaynaklanan etkilerle bitki boylarında değişmeler olmuştur. Örneğin "P-6480" $151.8 \mathrm{~cm}$ lik ortalama gösterirken "P-6431" $159.2 \mathrm{~cm}$ ( I.lokalde 174.6 $\mathrm{cm}$, II lokalde $143.9 \mathrm{~cm}$ ) olmuş ve genetik yapı ve çevre etkisi daha belirginleşmiştir aynı sonuç " Dekalb " serisindede gözlenmektedir.. Ancak "P-3628" de farklı bir durum görülmemiştir.

Tabla çapı: Tabla çapına ait değerler Çizelge 3 ve Çizelge 11.'de verilmiştir. I. lokalde bitkilerde tabla çapı ortalama $21.0-26.7 \mathrm{~cm}$, 11. lokalde ise $18.3-25.7 \mathrm{~cm}$ arasında değişmiştir. Tabla çapında anormal bir değişim olmamış ve ideal tabla çapı özelliği görülmüştür. Çeşitler arasında istatistiksel olarak \% 1 düzeyinde önemlilik kaydedilirken, çeşit x yer interaksiyonu önemsiz olmuştur. Tabla çapı genetik yapıya bağlı olarak farklı çeşitlerde dar veya geniş çaplı olabilir. Ayçiçeği ıslahçıları özellikle yağlık çeşitlerde 22 - $25 \mathrm{~cm}$ çapında tabla oluşumunu amaçlarlar. llisulu ve Arslan (1975) ortalama tabla çapını 22 - $25 \mathrm{~cm}$, Ekiz (1980 a) $18.9 \mathrm{~cm}$, Ekiz (1980 b) 17.4 cm, Oral ve Kara (1989) 21-22 cm, Sezer (1991) 17.8 . $21.0 \mathrm{~cm}$, Camci (1992) $14.0-19.0 \mathrm{~cm}$, Yilmaz ve Emiroğlu (1995) ise 16.6-22.7 cm arasında kaydettiklerini belirtmişlerdir. Tabla çapı bakımından araştırıcıların vermiş olduğu verilerle önemli farklılık ortaya çıkmamıştır. Ideal tabla çapi elde edilmiştir. "Ekiz" ve "Pioneer" serileri diğer çeşitlere göre daha kucçük tabla oluşturmuştur. Yapılan gözlemlerde tabla dolumunun iyi olduğu ve tabla orta boşluğunun oluşmadığı gözlemler içerisinde kaydedilmiştir.
Çizelge 8. Denemeye alınan ayçiçeği çeşitlerine ait Yağ verimi ve Duncan grupları

\begin{tabular}{|c|c|c|c|}
\hline Cesitler & \multicolumn{3}{|c|}{ Yă̆ verimi (kg/da) } \\
\hline & S.Urfa & K.Maras & Ortalama \\
\hline EDIRNE 87 & $98.8 \mathrm{a}$ & $78.8 \mathrm{c}-\mathrm{h}$ & $88.8 \mathrm{a}$ \\
\hline DEKALB TR 3891 DK & $97.1 \mathrm{ab}$ & $68.1 \mathrm{~g}-\mathrm{k}$ & $82.7 \mathrm{a}-\mathrm{c}$ \\
\hline PIONEER 6480 & $97.7 \mathrm{a}$ & $70.9 \mathrm{f}-\mathrm{j}$ & $84.3 \mathrm{ab}$ \\
\hline BASEGENE ST 115 & $86.7 \mathrm{a}-\mathrm{f}$ & $60.91-1$ & $73.8 \mathrm{~b}-\mathrm{d}$ \\
\hline EKiz1 & $96.3 \mathrm{a}-\mathrm{c}$ & $51.7 \mathrm{k}-1$ & $74.0 \mathrm{~b}-\mathrm{d}$ \\
\hline BASEGENE ST 117 & $95.9 \mathrm{a}-\mathrm{c}$ & 44.41 & $70.2 \mathrm{~d}$ \\
\hline PIONEER 6431 & $97.0 \mathrm{a}-\mathrm{b}$ & $57.4 \mathrm{j}-1$ & $77.2 \mathrm{a}-\mathrm{d}$ \\
\hline VNIIMK & $83.7 \mathrm{a}-\mathrm{g}$ & $61.5 \mathrm{~h}-1$ & $72.6 \mathrm{~b}-\mathrm{d}$ \\
\hline PIONEER 3628 & 91.3 a-e & $77,2 \mathrm{~d}-1$ & $84.3 \mathrm{ab}$ \\
\hline EKIZ II & $92.8 \mathrm{a}-\mathrm{d}$ & 48.31 & $70.6 \mathrm{~cd}$ \\
\hline GLINES TOH. IS 3330 & $79.1 \mathrm{~b}-\mathrm{h}$ & $51.8 \mathrm{~kJ}$ & $65.5 \mathrm{~d}$ \\
\hline DEKALB TR 3628 & $170.5 \mathrm{f}-\mathrm{j}$ & $74.5 \mathrm{e}-\mathrm{j}$ & $72.5 \mathrm{~b}-\mathrm{d}$ \\
\hline Ortalamalar & 90.6 & 62.2 & 76.4 \\
\hline Ő.D. & 0.01 & 0,01 & 0.01 \\
\hline
\end{tabular}

Çizelge 9. Denemeye alınan ayçiçeği çeşitlerine ait kabuk oranlan ve Duncan grupları

\begin{tabular}{|l|l|l|l|}
\hline Cesitter & \multicolumn{3}{|c|}{ Kabuk orani (\%) } \\
\hline & S.Urfa & K.Maraș & Ortalama \\
\hline EDIRNE 87 & $28.2 \mathrm{eg}$ & $29.9 \mathrm{gh}$ & $29.0 \mathrm{de}$ \\
\hline DEKALB TR 3891 DK & $25.1 \mathrm{ae}$ & $26.9 \mathrm{cg}$ & $26.0 \mathrm{ab}$ \\
\hline PIONEER 6480 & $27.9 \mathrm{dg}$ & $28.3 \mathrm{fg}$ & $28.0 \mathrm{ce}$ \\
\hline BASEGENE ST 115 & $31.4 \mathrm{~h}$ & $26.9 \mathrm{cg}$ & $29.1 \mathrm{e}$ \\
\hline EKIZ1 & $25.6 \mathrm{bf}$ & $25.9 \mathrm{bf}$ & $25.7 \mathrm{ab}$ \\
\hline BASEGENE ST 117 & $24.8 \mathrm{ad}$ & $25.9 \mathrm{bf}$ & $25.4 \mathrm{ab}$ \\
\hline PIONEER 6431 & $23.6 \mathrm{ab}$ & $25.6 \mathrm{bf}$ & $24.6 \mathrm{a}$ \\
\hline VNIIMK & $25.9 \mathrm{bf}$ & $22.7 \mathrm{a}$ & $24.3 \mathrm{a}$ \\
\hline PIONEER 3628 & $27.1 \mathrm{cg}$ & $27.0 \mathrm{cg}$ & $27.1 \mathrm{bcd}$ \\
\hline EKIZ II & $27.5 \mathrm{cg}$ & $24.4 \mathrm{ac}$ & $26.0 \mathrm{ab}$ \\
\hline GUNES TOH. IS 3330 & $27.4 \mathrm{cg}$ & $26.5 \mathrm{bf}$ & $27.0 \mathrm{bc}$ \\
\hline DEKALB TR 3628 & $27.0 \mathrm{cg}$ & $27.5 \mathrm{cg}$ & $27.2 \mathrm{be}$ \\
\hline Ortalamalar & 26.7 & 26.5 & 26.6 \\
\hline Ö.D. & 0.01 & 0.01 & 0.01 \\
\hline
\end{tabular}

Çizelge 10. Denemeye alınan ayçiçeği çeşitlerine ait bitki boyları ve Duncan grupları

\begin{tabular}{|c|c|c|c|}
\hline Çeșitler & \multicolumn{3}{|c|}{ Bitki boyu (cm) } \\
\hline & Ș.unfa & KMaraș & Ortalama \\
\hline EDIRNE 87 & 149.5 be & 153.8 be & 151.6 \\
\hline DEKALB TR 3891 DK & $171.5 \mathrm{ac}$ & $153.8 \mathrm{be}$ & 162.6 \\
\hline PIONEER 6480 & 151.7 be & 151.9 be & 151.8 \\
\hline BASEGENE ST 115 & $166.9 \mathrm{ad}$ & $147.5 \mathrm{ce}$ & 157.2 \\
\hline$E K \mid Z 1$ & $153.6 \mathrm{be}$ & 157.8 be & 155.7 \\
\hline BASEGENE ST 117 & $147.8 \mathrm{ce}$ & $163.0 \mathrm{ad}$ & 155.4 \\
\hline PIONEER 6431 & $174.6 \mathrm{ab}$ & $143.9 \mathrm{de}$ & 159.2 \\
\hline VNIIMK & $148.2 \mathrm{be}$ & $183.3 \mathrm{a}$ & 165.8 \\
\hline PIONEER 3628 & 156.7 be & $151.8 \mathrm{be}$ & 154.2 \\
\hline$E K \backslash Z \|$ & $146.3 \mathrm{ce}$ & 149.3 be & 147.8 \\
\hline GUNES TOH. IS 3330 & $165.9 \mathrm{ad}$ & $156.9 \mathrm{be}$ & 161.4 \\
\hline DEKALB TR 3628 & $136.3 \mathrm{e}$ & $162.0 \mathrm{ae}$ & 149.1 \\
\hline Ortalamalar & 155.7 & 156.2 & 155.9 \\
\hline O.D. & 0.01 & 0.01 & n.s. \\
\hline
\end{tabular}


Çizelge11. Denemeye alınan ayçiçeği çeşitlerine ait tabla çapları ve Duncan grupları

\begin{tabular}{|l|l|l|l|}
\hline Çeşitler & \multicolumn{3}{|c|}{ Tabla çapI (cm) } \\
\hline & S. Urfa & K.Maraş & Ortalama \\
\hline EDIRNE 87 & $26.7 \mathrm{a}$ & $25.7 \mathrm{ab}$ & $26.3 \mathrm{a}$ \\
\hline DEKALB TR 3891 DK & $26.3 \mathrm{a}$ & $23.8 \mathrm{~cd}$ & $25.1 \mathrm{a}$ \\
\hline PIONEER 6480 & $21.0 \mathrm{e}-\mathrm{h}$ & $18.7 \mathrm{j}$ & $19.9 \mathrm{c}$ \\
\hline BASEGENE ST 115 & $22.2 \mathrm{c}-\mathrm{f}$ & $18.3 \mathrm{j}$ & $20.3 \mathrm{bc}$ \\
\hline EKIZ1 & $21.3 \mathrm{e}-\mathrm{g}$ & $19.2 \mathrm{~h}-\mathrm{j}$ & $20.3 \mathrm{bc}$ \\
\hline BASEGENE ST 117 & $20.7 \mathrm{e}-\mathrm{f}$ & $19.7 \mathrm{~g}-\mathrm{j}$ & $26.2 \mathrm{bc}$ \\
\hline PIONEER 6431 & $22.6 \mathrm{c}-\mathrm{e}$ & $20.5 \mathrm{f}-\mathrm{l}$ & $21.6 \mathrm{bc}$ \\
\hline VNIIMK & $22.5 \mathrm{c}-\mathrm{e}$ & $21.1 \mathrm{e}-\mathrm{h}$ & $21.8 \mathrm{~b}$ \\
\hline PIONEER 3628 & $22.1 \mathrm{c}-\mathrm{f}$ & $19.4 \mathrm{~g}-\mathrm{j}$ & $20.9 \mathrm{bc}$ \\
\hline EKIZ II & $21.4 \mathrm{e}-\mathrm{g}$ & $19.3 \mathrm{~h}-\mathrm{j}$ & $20.4 \mathrm{bc}$ \\
\hline GUNES TOH. IS 3330 & $24.0 \mathrm{~b}-\mathrm{c}$ & $19.8 \mathrm{~g}-\mathrm{j}$ & $22.0 \mathrm{~b}$ \\
\hline DEKALB TR 3628 & $22.0 \mathrm{~d}-\mathrm{f}$ & $18.5 \mathrm{j}$ & $20.3 \mathrm{bc}$ \\
\hline Ortalamalar & 22.76 & 20.35 & 21.5 \\
\hline O.D. & 0.05 & 0.05 & 0.01 \\
\hline
\end{tabular}

\section{Sonuç}

Farklı lokasyonlarda kurulmuş olan bu deneme sonuçlarına göre; I. lokasyonda "IS 3330", "Dekalb TR 3628 " ve "Vnımk 8931" in dışındaki tüm çeşitlerin. II. lokasyonda ise "Edirne 87", "P-3628" ve "Dekalb TR 3628 " Çeşitlerinin ümitvar olarak öncelikle tavsiye edilebileceği görülmektedir

\section{Kaynaklar}

Anonymous, 1994. Ayçiçeği Raporu. Hasat Dergisi, Yil: 10. Sayı 109 , S. $32-36$.

Camcı,H. 1992 Orobanşa Dayanıklı Genetik Erkısır Ayçiçeği (Helianthus annus L.) hatlarının Fertilleri ile Erkısır Bitkiler Arasında Melez ve Heterosis. AÜ Ziraat Fakültesi Tarla BitkileriBölümü Doktora Tezi 61 s. Ankara

Demir,I. 1990. Genel Bitki Islahı. Ege Univ. Ziraat Fakültesi Yay No: $496366 \mathrm{~s}$. Bornova Izmir.

Ekiz E. 1980 (a.) Ayçiçeği (Helianthus annus L.) kardeş döllerinde Farklı Yöntemlerle DölGeliştirilmesi ve Sentetik Çeşit Elde EdilmesiA.U. Ziraat Fakütesi Yay. 736 BilimselAraştırmalarve Inc:427, $45 \mathrm{~s}$. Ankara

Ekiz E. 1980 (b) Ayçiçeği (Helianthus annus L.) kardeş döllerinde Farklı Yontemlerle DölGeliștirilmesi ve Sentetik Çeşit Elde Edilmesi. A.U. Ziraat Fakültesi Yay. 736, Bilimsel Araştırmalarve Inc: 427, 54 s. Ankara

Er, C. ve O., Işık, 1988. V.8931 Ayçiçeği Çeşitinde Ekim Zamanının Bazı Tarımsal Karakterlere Etkisi. Doğa, T.O.D., Vol. 12 (1) s: 19 - 23, Ankara
Gumenyuk, A.D. And M.S., Sytrik, 1976. Breeding Sunflower for High Yield and Oil Content. International Sunflower Conference. Vol. 1. France.

llisulu, K, E. Ekiz Ve O. Arslan, 1982. Ayçiçeği Islahi ve Orabanşa Dayanıklı Çeşitlerin Kurak Şartlara Adaptasyonu. TÜBITAK Yay. No. 512, TOAG Seri No. 102, $45 \mathrm{~s}$., Ankara

Kara, K., 1984. Erzurum Ekolojik Koşullarında Bazı Yağlık Ayçiçeği (Helianthus annus L.) Çeşitlerinin Fenolojik, Morfolojik Özellikleri ile Verim ve verim Unsurlar üzerinde Bir Araştırma Atatürk Univ. Ziraat Fakültesi Tarla Bitkileri Doktora Tezi

Kolsarıcı, Ö., B. Gürbüz, H. Arıoğlu, ve C. Çalışkan, 1990 Türkiye'de Yağ Bitkileri Üretimi ve Sorunları, T.2.M.O. III. Teknik Kongresi Bildiri Kitabı, 8 - 12 Ocak, s. 323 - 337. Ankara

Konstantinous, K. S. Ratkovic, S., Kapor, 1973. Fatty Acid Composition of Sunflower (H.annus) Varieties and $F_{1}$ Plants. Proc. The $6^{\text {th }}$ Int. Sunflower Conf. 22- 24 July. Bucharest-Romania

Majid, H.R. And A.A. Schneifer, 1987. Yield and Quality of Semidwarf and Standart Height Sunflowers Hybrids at Five Plant Populations. Agronomy Journal, 79 (4), p. 681 684

Marquard, R., 1980, Einfluss von Standart Factoren und Spezifaschen Klimakonstelationen Auf Felt Gehald. Feldsaurezusamensetzung und tokopherol gehald von raps, sonnen blumen, soja und leinhabilitations scrift an de universitat Gisessen.

Oral. E. Ve K. Kara, 1989, Erzurum Ekolojik Koşullarinda Bazı Yağlık Ayçiçeği Çeşitleri Üzerinde Bir Araştırma. DOĞA, TOAG Dergisi, 13:2, s.342 - 355, Ankara

Potler. T.D. and P.I., Mcloud, 1985. Evalation of Sunflower Cultivars in South Australia. Australian Journal of Experimental Agriculture, vol. 25 (3) p. 178-182

Sezer. N. 1987 , Orobanşa Dayanıklı " HS20" Erkısır Ayçiçeği Hattı ile Orobanşa Dayanıkı "Vniimk 8931" Ayçiçeği Hattı Arasında Melez ve Heterosis. Ankara Üniversitesi Fen Bilimleri Enstitusü Y.Lisans Tezi. $71 \mathrm{~s}$, Ankara (Basılmamıs)

Sezer C 1991. Orabanşa Dayanıklı Ayçiçeği Hatlanı ile Dayanıklı Genetik Erkısır Hatlar Arası Melez ve Heterosis. A.U. Ziraat Fak. Tarla Bitkileri Bölumu, Doktora Tezi, $65 \mathrm{~s}$, Ankara (Basılmamış)

Yılmaz,H,A., Emiroğlu, Ş.E 1995. Hibrit Ayçiçeği ( Helianthus annus L.) Islahinda Orobanş'a Dayanıklilık, Verim, Verim Unsurları ve Bazı Kimyasal Karakterler Üzerinde Araştırmalar. Tr.J of Agriculturre and Forestry ,19, s. $397-406$. 